\title{
Quantitative models for microstructure and thermal conductivity of vermicular graphite cast iron cylinder block based on cooling rate
}

\author{
Qing-yi Liu', Xiao-fu Zhang', Yu-cheng Sun', Ai-long Jiang1, Ji-chao Li', Hong-liang Zheng', *Xue-lei Tian² \\ 1. State Key Laboratory of Engine Reliability, Weichai Power Co., Ltd., Weifang 261001, China \\ 2. Key Laboratory for Liquid-Solid Structural Evolution and Processing of Materials, Ministry of Education, School of Materials Science and \\ Engineering, Shandong University, Jinan 250061, China
}

\begin{abstract}
The relationships of cooling rate with microstructure and thermal conductivity of vermicular graphite cast iron (VGI) cylinder block were studied, which are important for design and optimization of the casting process of VGI cylinder blocks. Cooling rates at different positions in the cylinder block were calculated based on the cooling curves recorded with a solidification simulation software. The metallographic structure and thermal conductivity were observed and measured using optical microscopy (OM), scanning electrical microscopy (SEM) and laser flash diffusivity apparatus, respectively. The effects of the cooling rate on the vermicularity, total and average areas of all graphite particles, and the pearlite fraction in the VGI cylinder block were investigated. It is found that the vermicularity changes in parabola trend with the increase of cooling rate. The total area of graphite particles and the cooling rate at eutectoid stage can be used to predict pearlite fraction well. Moreover, it is found that the thermal conductivity at room temperature is determined by the average area of graphite particles and pearlite fraction when the range of vermicularity is from $80 \%$ to $93 \%$. Finally, the quantitative models are established to calculate the vermicularity, pearlite fraction, and thermal conductivity of the VGI cylinder block.
\end{abstract}

Key words: vermicular graphite cast iron; cylinder block; quantitative model; cooling rate; thermal conductivity CLC numbers: TG143.49 Document code: A Article ID: 1672-6421(2021)01-052-08

\section{Introduction}

Cast iron can be classified into flake graphite, spheroidal graphite, malleable and vermicular graphite cast iron according to graphite morphology. Various graphite morphologies give cast iron different mechanical and thermal properties. Particular graphite morphology gives vermicular graphite cast iron (VGI) an excellent comprehensive performance compared with traditional gray cast iron ${ }^{[1-2]}$. VGI has become a promising material for new generation high power diesel engine castings such as cylinder blocks and heads, which can not only further improve the performance of engine, but also achieve the lightweight of engine ${ }^{[3-6]}$.

The thermal conductivity is of significant importance, and affects the resistance to thermal fatigue and distortion ${ }^{[7]}$, especially for cylinder blocks and heads with

*Xue-lei Tian

Male, born in 1963, Professor. His research interests mainly focus on liquidsolid structural evolution.

E-mail: tianxuelei@sdu.edu.cn;

Received: 2020-04-28; Accepted: 2020-11-11 nonhomogeneous temperature distributions in service. Many researchers ${ }^{[8-10]}$ have focused on the effects of microstructure including graphite morphology, graphite amount and pearlite fraction on thermal conductivity of cast iron. Matsushita et al. ${ }^{[8]}$ studied the influence of the nodularity on the thermal conductivity and corrected the traditional thermal conductivity model for ductile cast iron by changing the thickness of cuboid castings. Ma et al. ${ }^{[9]}$ found that when the vermicularity $(40 \%-90 \%)$ increased, the thermal conductivity of VGI increased, according to the numerical simulation by finite element software ANSYS. Wu et al. ${ }^{[10]}$ found that the thermal conductivity of VGI decreased with increasing pearlite content $(10 \%-80 \%)$ by finite element numerical simulation. These studies provide a reference for studying the quantitative effect of microstructure on thermal conductivity of VGI cylinder blocks and heads. Moreover, some studies have proved that it is feasible to predict microstructure and thermal conductivity of cast iron based on cooling rates. The cooling rate is the main factor that affects the microstructure and properties of cast iron under the same experimental conditions ${ }^{[11-12]}$. Xie et al. ${ }^{[13]}$ 
constructed the dynamic solidification curve for hypoeutectic gray cast iron by determining the exact positions of several critical points such as starting and ending points of eutectic solidification on the cooling curves. Characteristics of the microstructure were subjected to each critical point on the cooling curves. Consequently, cooling rates calculated by cooling curves can be used to predict characteristics of the microstructure. Daniel et al. ${ }^{[14]}$ took cylindrical castings as the research object and studied the effect of solidification rate on the thermal conductivity of gray cast iron by changing the moulding material (metal, sand and insulation) and found that the optimal thermal transport properties could be obtained at medium cooling rates (sand mould). Therefore, the cooling rate, microstructure and thermal conductivity are interrelated. The cooling rate directly affects the evolution of microstructure which determines thermal conductivity.

The present work took a VGI cylinder block as the research object. The cooling rates at different positions in the cylinder block were calculated based on the cooling curves obtained by casting process numerical simulation software, MAGMA software ${ }^{[15]}$.
Then, based on the quantitative analysis of metallography and the statistical analysis of experimental data, including vermicularity, pearlite fraction and thermal conductivity, the quantitative effects of the cooling rate on the microstructure and thermal conductivity of VGI cylinder block were investigated. Finally, the quantitative models based on cooling rate were established to predict the vermicularity, pearlite fraction and thermal conductivity for VGI cylinder block. The results are helpful for the design and optimization of casting process of VGI cylinder block.

\section{Experimental methods}

\subsection{Materials}

The cylinder block was produced on the HWS moulding line with green sand mould. The combination of wire feeding technology and on-line detection technology (OCC Gmbh, Germany) was used for liquid iron quality detection and control. Table 1 shows the chemical composition of the liquid iron analyzed by a carbon-sulfur analyzer and Spectro direct-reading spectrometer.

Table 1: Chemical composition of VGI cylinder block (wt.\%)

\begin{tabular}{cccccccccccccc}
$\mathbf{C}$ & $\mathrm{Si}$ & $\mathrm{Mn}$ & $\mathrm{P}$ & $\mathrm{S}$ & $\mathrm{Mg}$ & $\mathrm{Cu}$ & $\mathrm{Sn}$ & $\mathrm{Mo}$ & $\mathrm{Ni}$ & $\mathrm{Fe}$ \\
\hline 3.790 & 2.180 & 0.405 & 0.032 & 0.016 & 0.011 & 0.678 & 0.066 & 0.032 & 0.011 & Bal.
\end{tabular}

\subsection{Acquisition of cooling curve}

The solidification process of the VGI cylinder block was simulated by MAGMA software, and 63 cooling curves were recorded at different positions on three sections of the cylinder block, which are the end section [Fig. 1(a,b)], quarter section [Fig. 1(c, d)] and central section [Fig. 1(e, f)]. This would ensure that the cooling rate range of the cylinder block was fully represented. Ten cooling curves were selected among the 63 curves based on that the eutectic cooling rates being at an equal interval. The 10 cooling curves were recorded at the positions of the red rectangles as shown in Fig. 1, and the cooling curves are shown in Fig. 2.

\subsection{Metallography}

The 10 VGI specimens were obtained at the positions corresponding to those of the 10 cooling curves. The microstructure of the VGI specimens was examined using the OM (LWD200-4XC). As position marks, nine grids were drawn with a needle on the surface of each specimen then the fields of view were easily located at the same position before and after etching. The area of each phase was obtained by counting the number of pixels in metallographic image. The unetched specimens were used to acquire the area of graphite and the vermicularity was calculated according to the Chinese Standard GB/T 26655-2011. Then, the specimens were etched with $4 \%$ nital for 5-7 s. The area of ferrite was also obtained by counting the number of pixels in metallographic image. The pearlite fraction was calculated by $\left(S_{\text {Field }}-S_{\text {Graphite }}-S_{\text {Ferrite }}\right) /\left(S_{\text {Field }}\right.$
- $S_{\text {Graphite }}$ ), where $S_{\text {Graphite, }} S_{\text {Ferrite }}$ and $S_{\text {Field }}$ represent the area of graphite, ferrite phase and the field of view, respecitively.

\subsection{Thermal conductivity testing}

The thermal diffusivity was measured using a laser flash apparatus (Netzsch LFA457, Germany). Then, the thermal conductivity was calculated according to $\lambda=a \rho C_{\mathrm{p}}$, where $a$ is the measured thermal diffusivity, $\rho$ is the bulk density and $C_{\mathrm{p}}$ is the specific heat ${ }^{[16]}$. The specimens with dimensions of $\Phi 12.5 \mathrm{~mm} \times 2 \mathrm{~mm}$ were cut using a linear cutting machine. The surface of every specimen was polished to ensure the reliability of thermal conductivity testing. The thermal conductivity of each specimen was the average value of three measurements at room temperature.

\section{Results and discussion}

\subsection{Calculation of cooling rate}

As shown in Fig. 2, the change of cooling curves is complex and the entire cooling process cannot be expressed by the cooling rate at a single stage. In order to accurately describe the overall trend of each cooling curve, the eutectic and eutectoid cooling rates were calculated, respectively. Graphite is formed during the eutectic stage and the graphite morphology is directly related to the cooling rate at the eutectic stage ${ }^{[17-18]}$. The average cooling rate at eutectic stage was calculated by $V_{\text {Eutectic }}=\Delta T /\left(t_{2}\right.$ $-t_{1}$ ), where $\Delta T$ represents the equivalent temperature difference that can be calculated by $\Delta T=L / C_{\mathrm{p}}$, where $L$ is latent heat and 

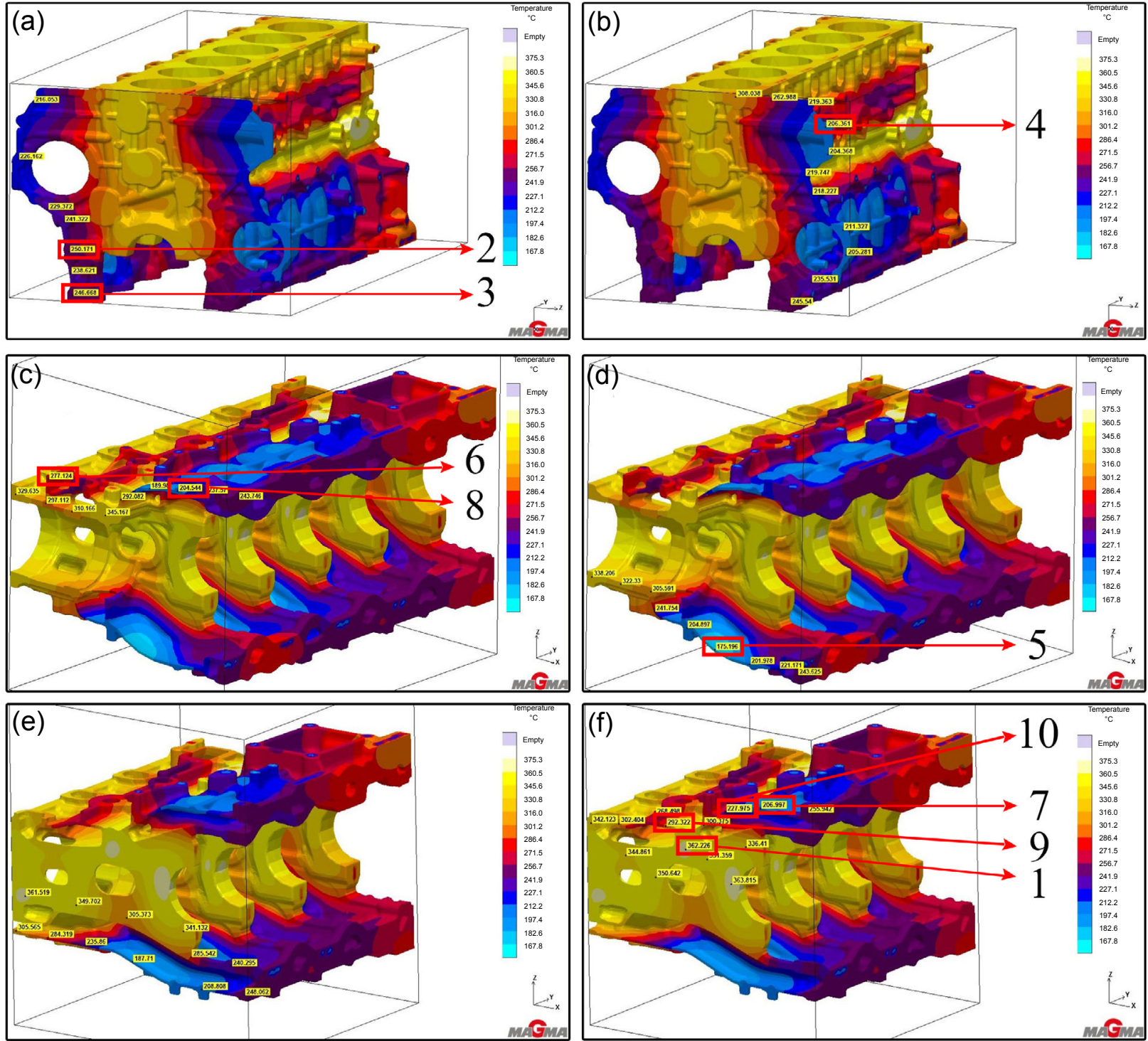

Fig. 1: Numerical simulation results of solidification at end section ( $a$ and b), quarter section (c and d), and central section (e and $f)$

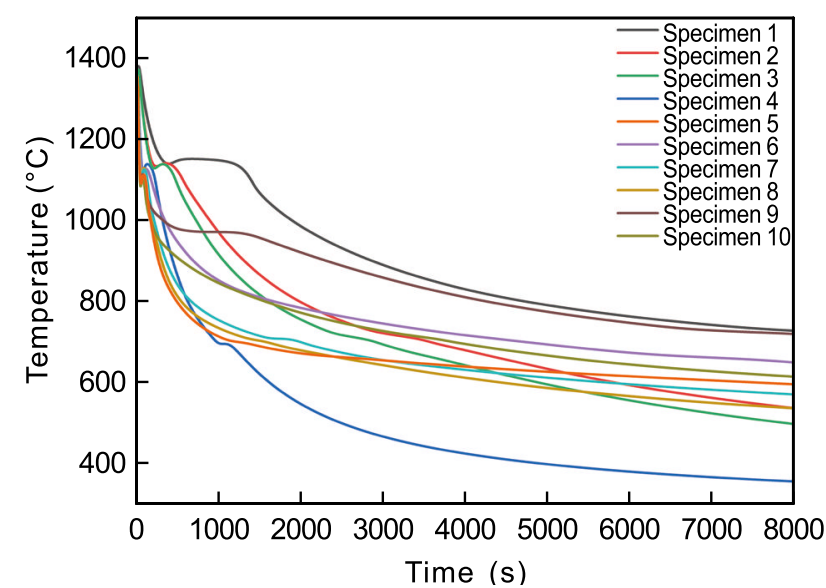

Fig. 2: Cooling curves for 10 selected positions in cylinder block

$C_{\mathrm{p}}$ is specific heat. Calculations are based on the premise that the heat released by the drop of $\Delta T$ is equal to that released by the latent heat at the eutectic stage. Points $t_{1}$ and $t_{2}$ are the intersections of the cooling curve and a horizontal line through the mid point of the highest and lowest temperatures at the eutectic stage, as shown in Fig. 3. The time from $t_{1}$ to $t_{2}$ covers the undercooling, recalescence process and most of the eutectic platform, which can correspond well to the non-nucleation, nucleation and growth process of graphite. Pearlite and ferrite

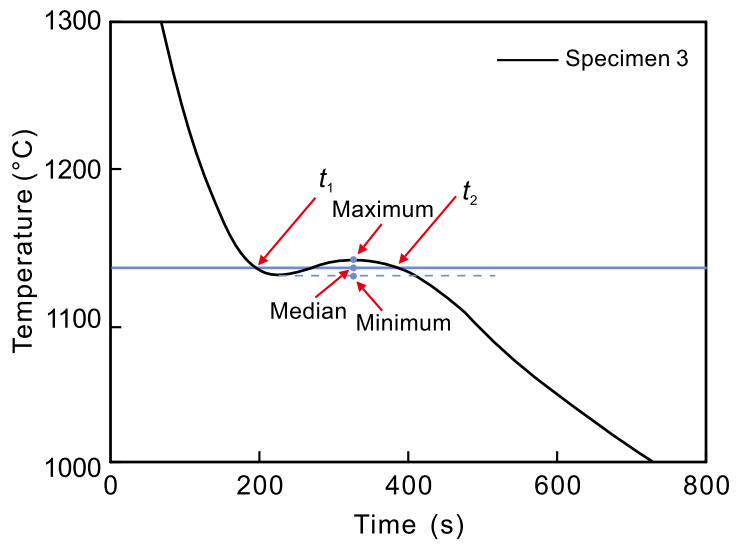

Fig. 3: Determining $t_{1}$ and $t_{2}$ by using cooling curve 
are formed during the eutectoid stage, and there is a direct correlation between the pearlite fraction and cooling rate at the eutectoid stage. The eutectoid stage was calculated according to $V_{\text {Eutectoid }}=(750-680) /\left(t_{4}-t_{3}\right)$, where $t_{3}$ and $t_{4}$ represent the time taken to cool the melt to $750{ }^{\circ} \mathrm{C}$ and $680{ }^{\circ} \mathrm{C}$, respectively. The temperature range of $750{ }^{\circ} \mathrm{C}$ to $680{ }^{\circ} \mathrm{C}$ covers the eutectoid temperature of all specimens.

Figure 4 shows the calculated cooling rates of the 10 specimens at the eutectic and eutectoid stages. The ranges of eutectic and eutectoid cooling rates are from $0.56{ }^{\circ} \mathrm{C} \cdot \mathrm{s}^{-1}$ to $8.91{ }^{\circ} \mathrm{C} \cdot \mathrm{s}^{-1}$ and $0.01{ }^{\circ} \mathrm{C} \cdot \mathrm{s}^{-1}$ to $0.17{ }^{\circ} \mathrm{C} \cdot \mathrm{s}^{-1}$, respectively. The 10 specimens were selected among the 63 positions based on the eutectic cooling rates being at an equal interval. However, the distribution of the eutectoid cooling rate of specimens was not at equal intervals, and the order of eutectoid cooling rate was not consistent with that of eutectic cooling rate, such as in Specimens 5 and 10, where the eutectoid cooling rate of Specimen 5 is the fastest, but its eutectic cooling rate is slower than that of Specimen 10. In contrast, Specimen 10 has the fastest eutectic cooling rate, but a slower eutectoid cooling rate

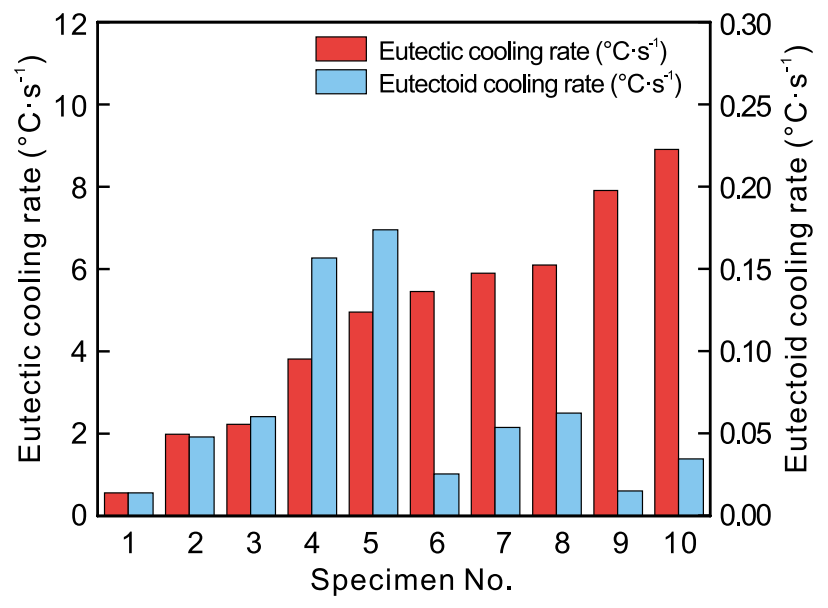

Fig. 4: Distribution of cooling rate at eutectic and eutectoid stages than Specimen 5. After the mold filling, there is little difference in the temperature of each part of the sand mold. Therefore, the cooling rate at the eutectic stage of each position in the cylinder block is dependent on its thickness. During the solid cooling process, the cooling rate is affected not only by its own wall thickness, but also by the wall thickness of positions around it. This results that the positions with the same wall thickness show different eutectoid cooling rates and the order of eutectoid cooling rate is not consistent with that of eutectic cooling rate.

\subsection{Quantitative metallographic analysis}

The graphite morphologies in specimens at different positions in the cylinder block are shown in Fig. 5. It can be seen that with the eutectic cooling rate decreasing, the vermicular graphite gradually becomes slender. Meanwhile, the size of spheroidal graphite increases and the number of spheroidal graphite fluctuates. The vemicularity, total and average areas of all graphite particles of each specimen are shown in Fig. 6 and Fig. 7, respectively.

Vermicularity is the quantitative expression of a particular VGI graphite morphology, which has a major impact on the properties. It is important to establish a quantitative model between cooling rate and vermicularity. The curve in Fig. 6 was obtained by polynomial fitting, except for Specimen 1 whose eutectic cooling rate was much slower than that of the others, and Specimen 5 whose vermicularity (67\%) was much lower than $80 \%$. Equation (1) is the fitting formula corresponding to the red line in Fig. 6, which is applicable to the cooling rate range from $2{ }^{\circ} \mathrm{C} \cdot \mathrm{s}^{-1}$ to $9{ }^{\circ} \mathrm{C} \cdot \mathrm{s}^{-1}$ :

Vermicularity $(\%)=54.71+13.33 V_{\text {Eutectic }^{-}}-1.21 V_{\text {Eutectic }}^{2}$

and R-square: 0.88

where $V_{\text {Eutectic }}$ is the cooling rate at the eutectic stage.

As shown in Fig. 6, the vermicularity of most specimens is between $80 \%$ and $93 \%$. The higher vermicularity could be obtained when the eutectic cooling rate is in the range from $4{ }^{\circ} \mathrm{C} \cdot \mathrm{s}^{-1}$ to $7^{\circ} \mathrm{C} \cdot \mathrm{s}^{-1}$.
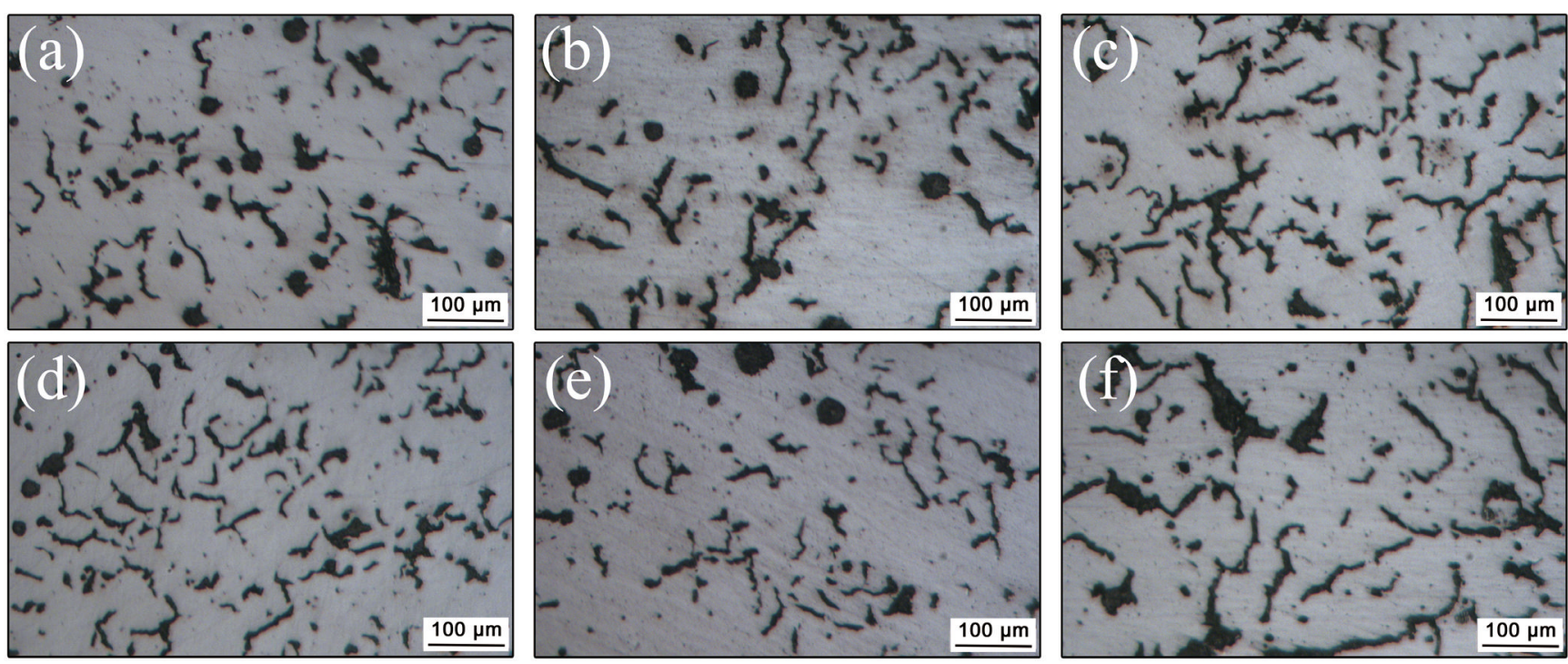

Fig. 5: Graphite morphologies in specimens at different positions in cylinder block, (a) to (f) show images for Specimens $10,9,8,6,3$ and 1 , respectively, sorting by cooling rate from fast to slow 


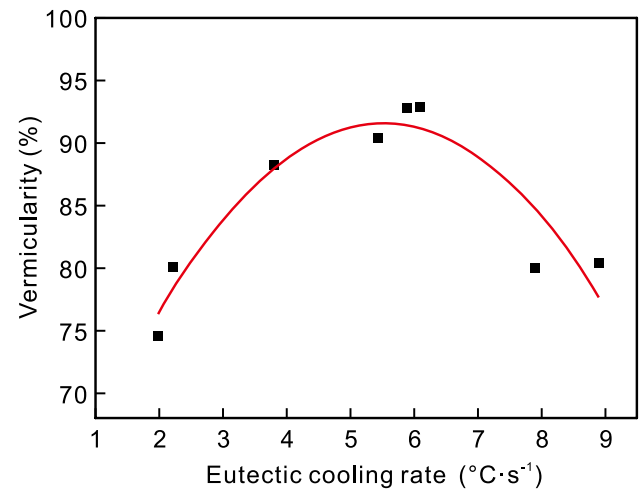

Fig. 6: Effect of eutectic cooling rate on vermicularity

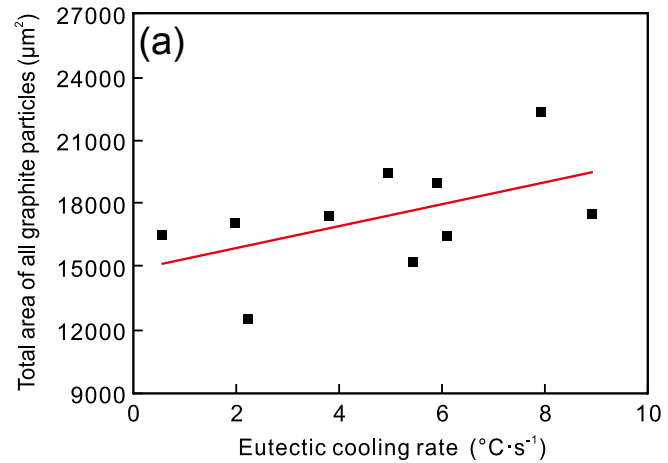

Graphite content and size have an effect on the matrix structure and thermal conductivity of VGI. Therefore, it is necessary to research the effect of cooling rate on graphite content and size. As shown in Figs. 7(a) and (b), the total area of all graphite particles increases, and the average area of graphite particles decreases with the increase of eutectic cooling rate. Consequently, the change of graphite content and size should be considered when establishing the quantitative model of matrix structure and thermal conductivity.

The morphology of the matrix after etching with $4 \%$ nital is shown in Fig. 8. It can be seen that the matrix of these specimens is mainly composed of pearlite and there is little difference in

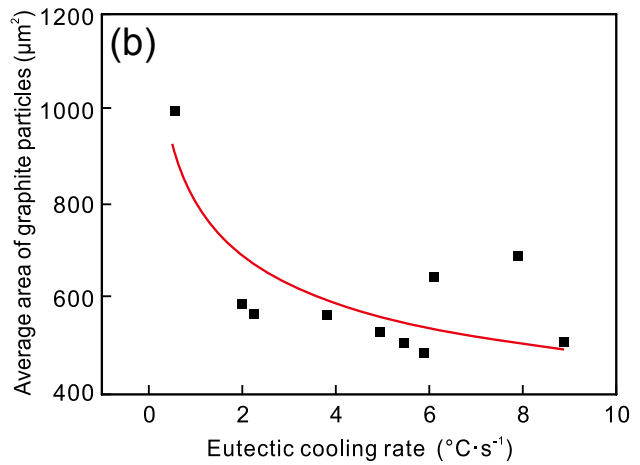

Fig. 7: Effect of eutectic cooling rate on total area (a) and average area (b) of graphite particles
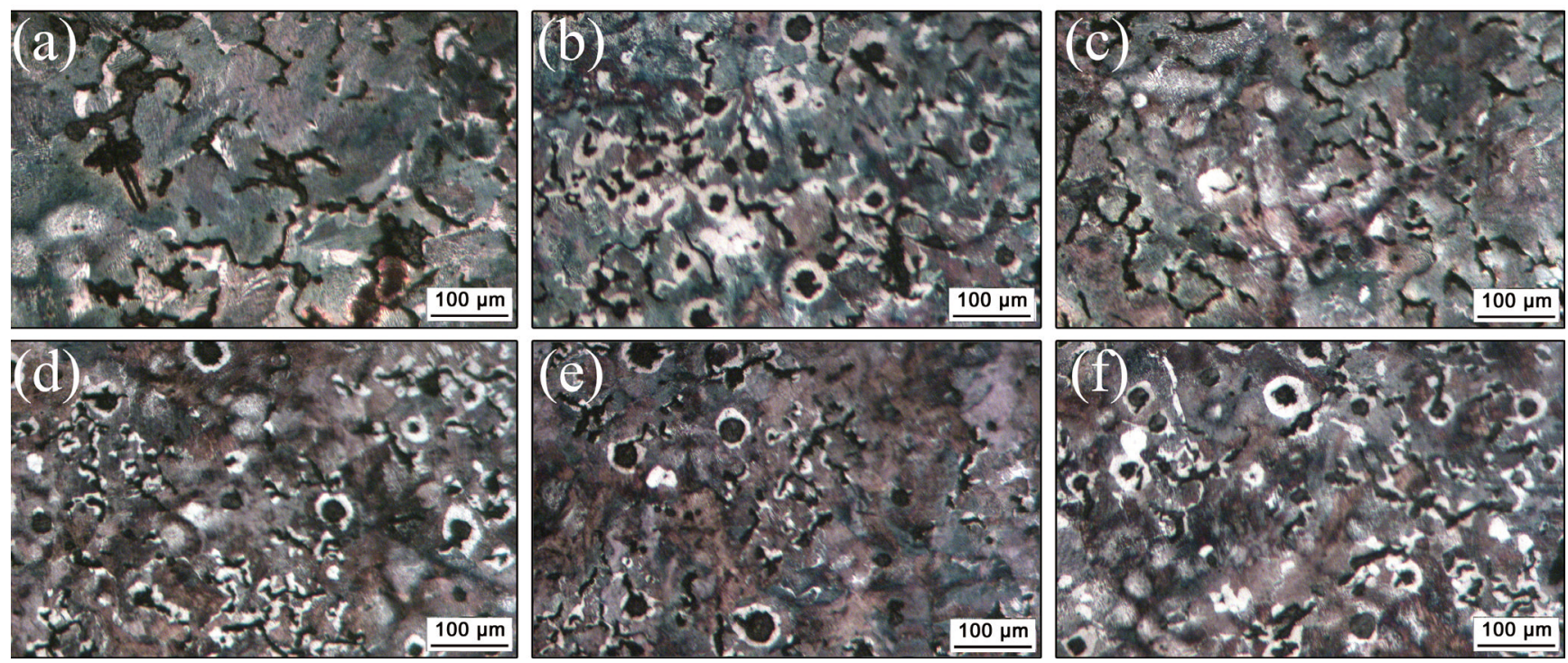

Fig. 8: Optical micrographs of specimens etched with $4 \%$ nital: (a) to (f) show images for Specimens 1, 10, 7, 3, 4 and 5 , respectively, sorting by cooling rate from slow to fast

the pearlite fraction. The pearlite fraction in each specimen is shown in Fig. 9. It is found that there is not an obvious monotonic relationship between the pearlite fraction and the eutectoid cooling rate. Therefore, the change of pearlite fraction cannot be well explained only by eutectoid cooling rate. However, it can be found in Fig. 9 that with the increase of the eutectoid cooling rate, the total area of all graphite particles changes in the completely opposite trend with the pearlite fraction. Consequently, the combination of total area of all graphite particles and the eutectoid cooling rate could be applied to accurately estimate the pearlite fraction of cylinder block, as shown in Eq. (2), which was obtained by binary polynomial fitting:

$$
\begin{aligned}
f_{\text {Pearlite }}= & 69.51+270.8 V_{\text {Eutectoid }}+3.26 \mathrm{e}(-3) S_{\text {Graphite }} \\
& +1058 V^{2} \text { Eutectoid } \\
& -1.11 \mathrm{e}(-7) S_{\text {Graphite }}^{2} \quad \text { R-square: } 0.76
\end{aligned}
$$

where $f_{\text {Pearlite }}$ is the pearlite fraction, $V_{\text {Eutectoid }}$ is the cooling rate at eutectoid stage and $S_{\text {Graphite }}$ is the total area of all graphite particles. 


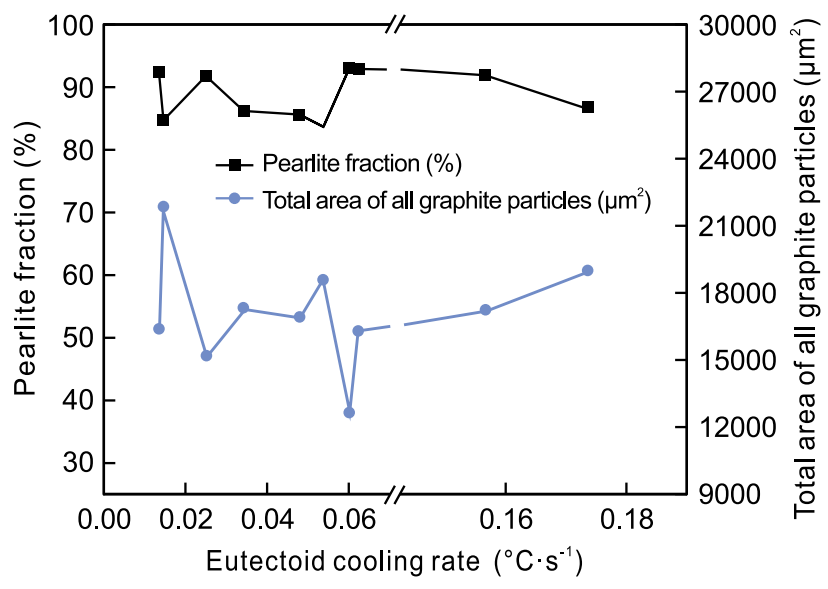

Fig. 9: Effect of eutectoid cooling rate on pearlite fraction and corresponding relation between the pearlite fraction and total area of all graphite particles

\subsection{Thermal conductivity}

The thermal conductivity at room temperature of specimens at different positions in the cylinder block is shown in Fig. 10, except for Specimens 5, 7 and 9, as it is difficult to obtain the qualified samples at those positions due to the complex shape of the cylinder block. The range of thermal conductivity is from $34.951 \mathrm{~W} \cdot \mathrm{m}^{-1} \cdot \mathrm{K}^{-1}$ to $38.904 \mathrm{~W} \cdot \mathrm{m}^{-1} \cdot \mathrm{K}^{-1}$. Previous investigations on thermal conductivity of VGI have concluded that parameters, such as additions of carbon (3.19wt.\%-6.67wt.\%) and silicon (1.89wt.\%-3.86wt.\%), nodularity (0-30\%), and fractions of ferrite $(0-30 \%)$, generally have great influence on the thermal conductivity as they vary in a wide range ${ }^{[19]}$. However, for the same cylinder block, the range of these parameters is narrow. Therefore, some parameters with a wide range, such as average area of graphite particles, should also have an effect on thermal conductivity. Matlab software was used to analyze the correlation between thermal conductivity and microstructure characteristics, including vermicularity, average area of graphite particles, total area of all graphite particles, and pearlite fraction. It was found that among all parameters, there was the best correlation between the average area of graphite particles and

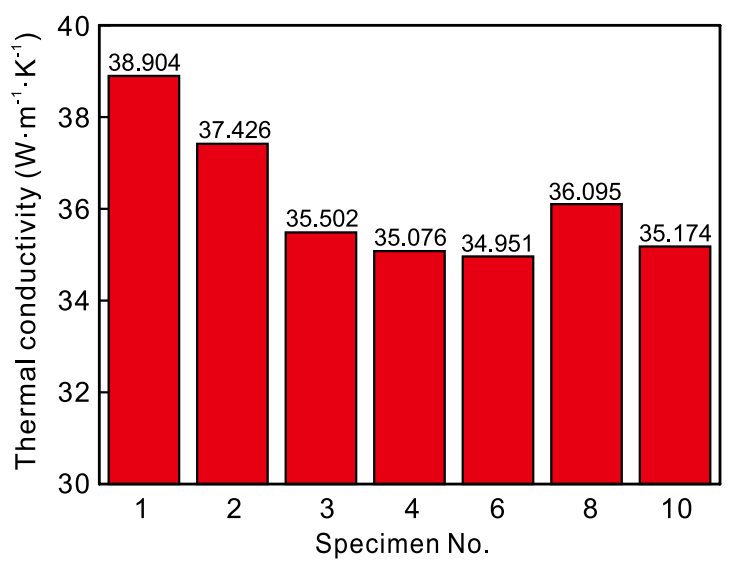

Fig. 10: Thermal conductivity of different specimens at room temperature thermal conductivity, and the correlation coefficient was 0.88 . Consequently, the average area of graphite particles is the main factor affecting thermal conductivity.

The specimens were reordered according to the thermal conductivity from low to high, and the relationship between the average area of graphite particles, pearlite fraction and thermal conductivity is shown in Fig. 11. In general, the thermal conductivity and the average area of graphite particles show the same changing trend. Among all specimens, the average area of graphite particles in Specimen 10 and Specimen 2 is smaller, but their thermal conductivity does not decrease due to the low pearlite fraction. Therefore, pearlite fraction is also a factor affecting thermal conductivity. By binary polynomial fitting, Eq. (3) was obtained:

$\lambda=45.88+8.77 \mathrm{e}(-3) \bar{S}_{\text {Graphite }}-0.17 f_{\text {Pearlite }}$ and R-square: 0.90

where $\lambda$ is the thermal conductivity at room temperature and $\bar{S}_{\text {Graphite }}$ is the average area of graphite particles.

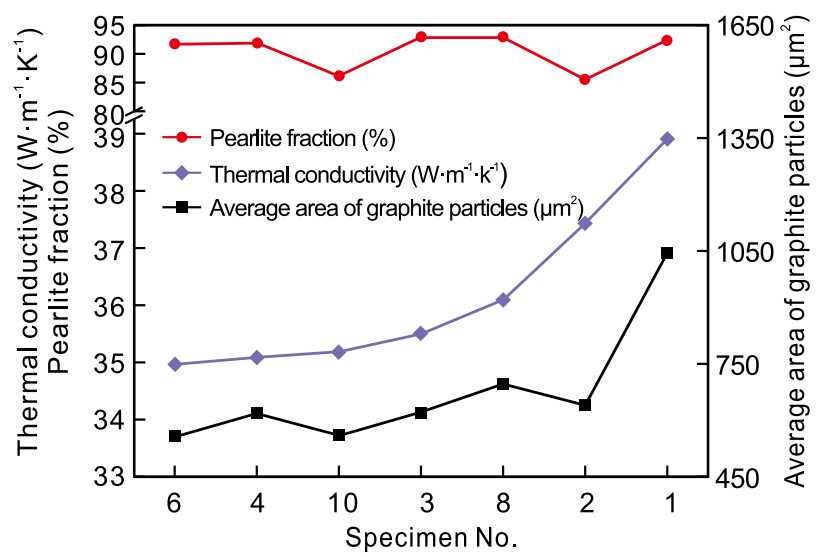

Fig. 11: Influence of average area of graphite particles and pearlite fraction on thermal conductivity at room temperature

It also indicates that generally the thermal conductivity at room temperature increases with an increase in the average area of graphite particles and a decrease in the pearlite fraction. Stereological characteristics of the graphite, such as the $3 \mathrm{D}$ connectivity, are essential for the thermal conductivity of VGI ${ }^{[20-21]}$. Three kinds of 2D connection forms between graphite particles, as shown in Fig. 12, can be seen in many specimens. It is considered that the increase of the average area of graphite particles, which represents the volume increase of each graphite, can raise the possibility of graphite contact. With the increase of connectivity, the thermal conductivity increases. After a great number of field observations, it was found that the third form [Fig. 12(f)] was more common in the specimen with higher thermal conductivity, which confirmed our conjecture.

As shown in Fig. 10, the thermal conductivity decreases with the increase of cooling rate at the eutectic stage. Consequently, the positions with slower eutectic cooling rates in the cylinder block have a higher thermal conductivity. The thermal conductivities at the hot spots are the highest herein, such as the position of Specimen 1: its thermal conductivity reaches $38.904 \mathrm{~W} \cdot \mathrm{m}^{-1} \cdot \mathrm{K}^{-1}$. 

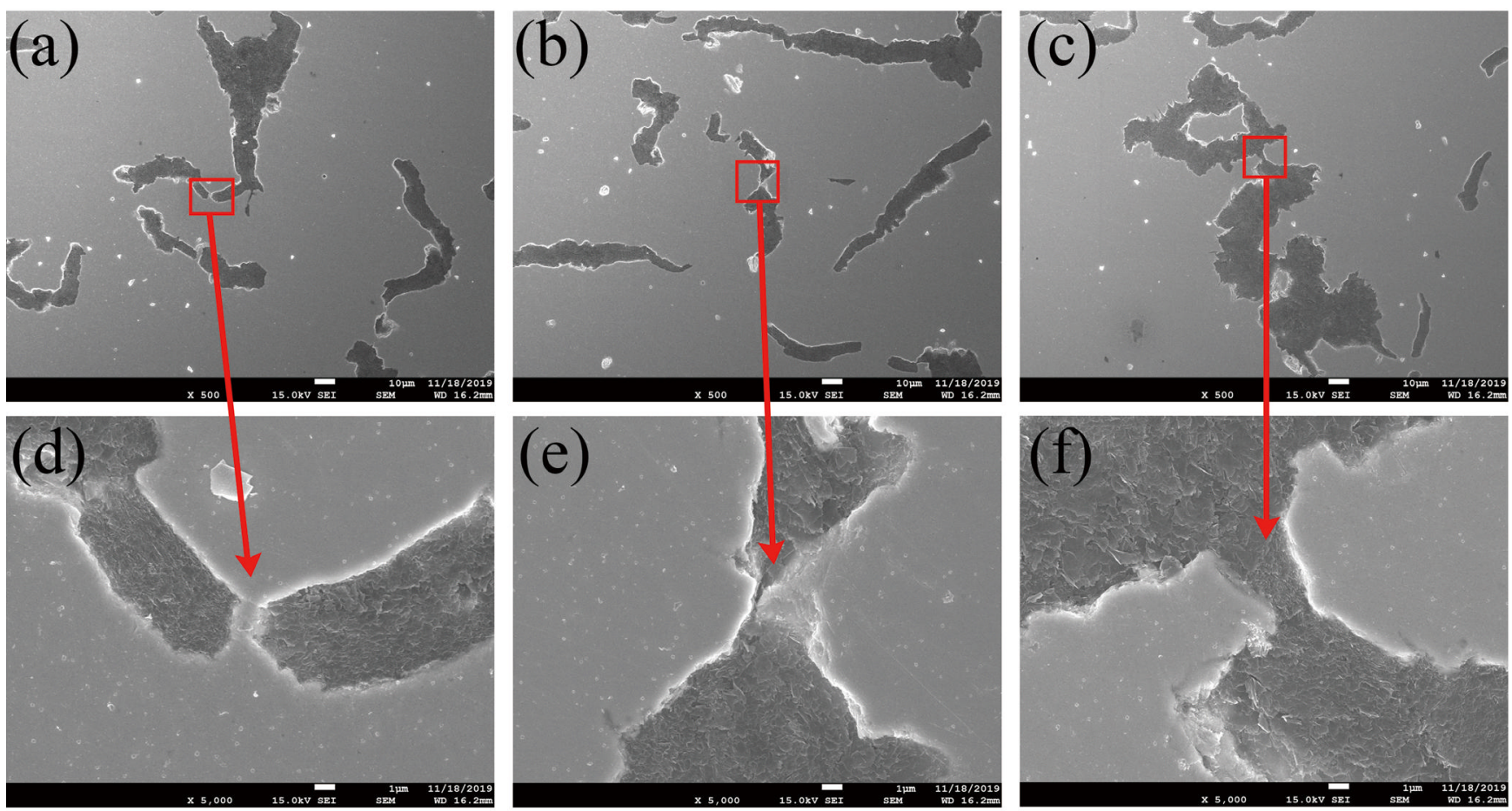

Fig. 12: Three kinds of 2D connection forms between graphite particles

The thermal conductivities of the thin-wall positions close to the sand mould and far away from a hot spot are lower, such as the position of Specimen 6 , which reaches $34.951 \mathrm{~W} \cdot \mathrm{m}^{-1} \cdot \mathrm{K}^{-1}$. Moreover, compared with the positions with the lowest thermal conductivity, the thin-wall positions near or connected to hot spots show a higher thermal conductivity (about $36 \mathrm{~W} \cdot \mathrm{m}^{-1} \cdot \mathrm{K}^{-1}$ ), such as the position of Specimen 8 .

In actual design and production, the cooling rate of each position in the cylinder block can be easily obtained by simulation. Meanwhile, the research results mentioned above show that the average area of graphite particles and pearlite fraction are closely related to eutectic cooling rate and eutectoid cooling rate, respectively. Therefore, a quantitative model for the thermal conductivity at room temperature based on the eutectic cooling rate and eutectoid cooling rate was obtained by binary polynomial fitting, as shown in Eq. (4):

$$
\begin{aligned}
\lambda= & 40.54-1.45 V_{\text {Eutectic }}-72.19 V_{\text {Eutectoid }}+0.06 V_{\text {Eutectic }}^{2} \\
& +17.69 V_{\text {Eutectic }} \cdot V_{\text {Eutectoid }} \\
& \text { and R-square: } 0.93
\end{aligned}
$$

The results indicate that a combination of the eutectic cooling rate and eutectoid cooling rate could be applied to accurately estimate the thermal conductivity $(\lambda)$ of VGI cylinder blocks.

\section{Conclusions}

The quantitative effects of the cooling rate on the microstructure and thermal conductivity of VGI cylinder block were studied. Based on the statistical analysis of experimental data, quantitative models were established to predict the vermicularity, pearlite fraction, and thermal conductivity for VGI cylinder block castings for which vermicularity variation range is narrow $(80 \%-93 \%)$. The quantitative models and main conclusions were summarized as follows:

(1) A polynomial fitting formula as a quantitative model was established to calculate vermicularity by eutectic cooling rate: Vermicularity $(\%)=54.71+13.33 V_{\text {Eutectic }}-1.21 V_{\text {Eutectic }}^{2}$. The vermicularity shows a parabolic trend with the increase of eutectic cooling rate within the range of $(2-9){ }^{\circ} \mathrm{C} \cdot \mathrm{s}^{-1}$. A higher vermicularity can be obtained when the eutectic cooling rate is in the range from $4{ }^{\circ} \mathrm{C} \cdot \mathrm{s}^{-1}$ to $7{ }^{\circ} \mathrm{C} \cdot \mathrm{s}^{-1}$. Moreover, total area of all graphite particles increases and average area of graphite particles decreases with an increase in eutectic cooling rate during non-equilibrium solidification process.

(2) The pearlite fraction of the cylinder block is determined by the combined action of the total area of all graphite particles and eutectoid cooling rate. The quantitative model with these two parameters was established:

$$
\begin{aligned}
f_{\text {Pearlite }}= & 69.51+270.8 V_{\text {Eutectoid }}+3.26 \mathrm{e}(-3) S_{\text {Graphite }} \\
& +1058 V_{\text {Eutectoid }}^{2}-2.55 \mathrm{e}(-2) V_{\text {Eutectoid }} \cdot S_{\text {Graphite }} \\
& -1.11 \mathrm{e}(-7) S_{\text {Graphite }}^{2}
\end{aligned}
$$

(3) The average area of graphite particles and the pearlite fraction are the main factors affecting the thermal conductivity of VGI cylinder block when the vermicularity is between $80 \%$ to $93 \%$. The combination of the eutectic cooling rate and eutectoid cooling rate could be applied to accurately estimate the thermal conductivity of VGI cylinder blocks. Two fitting formulas as the quantitative models are established to calculate thermal conductivity at room temperature based on the average area of graphite particles and pearlite fraction, and cooling 
rate, respectively:

$$
\begin{aligned}
\lambda= & 45.88+8.77 \mathrm{e}(-3) \bar{S}_{\text {Graphite }}-0.17 f_{\text {Pearlite }} \\
\lambda= & 40.54-1.45 V_{\text {Eutectic }}-72.19 V_{\text {Eutectoid }}+0.06 V_{\text {Eutectic }}^{2} \\
& +17.69 V_{\text {Eutectic }} \cdot V_{\text {Eutectoid }}
\end{aligned}
$$

\section{References}

[1] Shy $\mathrm{YH}$, Hsu C H, Lee S C, et al. Effects of titanium addition and section size on microstructure and mechanical properties of compacted graphite cast iron. Materials, 2000, 278: 54-60.

[2] Dawson S. Compacted graphite iron - a material solution for modern diesel engine cylinder block and heads. China Foundry, 2009, 6(3): 241-246.

[3] Zhang $X X$, Zhang G W, Xu H. Homogeneity research on microstructure and properties of vermicular graphite cast iron. Hot Working Technology, 2014, 43(13): 27-30.

[4] Wang X X, Zhou J R, Su W. Casting of cylinder block and cylinder head of engine. Journal of Netshape Forming Engineering, 2010, 2(6): 79-86.

[5] Zhang M X, Pang J C, Qiu Y, et al. Thermo-mechanical fatigue property and life prediction of vermicular graphite iron. Materials Science and Engineering: A, 2017, 698: 63-72.

[6] Soeudy R I E. The effect of graphite aspect ratio on the mechanical and microstructural properties of cast iron. Materialwissenschaft und Werkstofftechnik, 2002, 33(2): 73-79.

[7] Holmgren D. Review of thermal conductivity of cast iron. International Journal of Cast Metals Research, 2005, 18(6): 331-345.

[8] Matsushita T S, Albano G E, Lennart J, et al. On the thermal conductivity of $\mathrm{CGI}$ and $\mathrm{SGI}$ cast irons. International Journal of Cast Metals Research, 2018, 31(3): 135-143.

[9] Ma Zhijun, Tao Dong, Yang Zhong, et al. The effect of vermicularity on the thermal conductivity of vermicular graphite cast iron. Materials \& Design, 2016, 93: 418-422.

[10] Wu Y, Li J P, Yang Z, et al. Computational assessment of thermal conductivity of compacted graphite cast iron. Advances in Materials Science and Engineering, 2019(3): 1-7.
[11] Górny M, Tyrała E. Effect of cooling rate on microstructure and mechanical properties of thin-walled ductile iron castings. Journal of Materials Engineering and Performance. 2013, 22(1): 300-305.

[12] Salazar R, Herrera-Trejo M, Castro M, et al. Effect of nodule count and cooling rate on as-cast matrix of a Cu-Mo spheroidal graphite. Journal of Materials Engineering and Performance, 1999, 8(3): 325-329.

[13] Xie M G, Zhu C A. Construction and analysis of dynamic solidification curves for non-equilibrium solidification process in lost-foam casting hypoeutectic gray cast iron. China Foundry, 2017, 14(3): 176-183.

[14] Daniel H, Attila D, Ingvar L, et al. Effects of carbon content and solidification rate on thermal conductivity of grey cast iron. China Foundry, 2007, 4(3): 210-214.

[15] Neves S, Schäfer W, Hansen P N. The sensibility of thermophysical property data for simulating casting processes. International Journal of Thermophysics, 2002, 23(5): 1391 1399.

[16] Xu D M, Wang G Q, Chen X, et al. Effects of alloy elements on ductility and thermal conductivity of compacted graphite iron. China Foundry, 2018, 15(3): 189-195.

[17] Park J S, Verhoeven J D. Transitions between type A flake, type $D$ flake, and coral graphite eutectic structures in cast irons. Metallurgical and Materials Transactions A, 1996, 27(9): 2740-2753.

[18] Stefanescu D M, Alonso G, Larrañaga P, et al. Reexamination of crystal growth theory of graphite in iron-carbon alloys. Acta Materialia, 2017, 139: 109-121.

[19] Selin M, König M. Regression analysis of thermal conductivity based on measurements of compacted graphite irons. Metallurgical \& Materials Transactions A, 2009, 40(13): 3235-3244.

[20] Velichko A, Holzapfel C, Siefers A, et al. Unambiguous classification of complex microstructures by their threedimensional parameters applied to graphite in cast iron. Acta Materialia, 2008, 56(9): 1981-1990.

[21] Velichko A, Wiegmann A, Mücklich F. Estimation of the effective conductivities of complex cast iron microstructures using FIB-tomographic analysis. Acta Materialia, 2009, 57(17): 5023-5035. 